\title{
Inflammatory Pain and Corticosterone Response in Infant Rats: Effect of 5-HT1A Agonist Buspirone Prior to Gestational Stress
}

\author{
Irina P. Butkevich, ${ }^{1}$ Viktor A. Mikhailenko, ${ }^{1}$ Tat'yana R. Bagaeva, ${ }^{2}$ Elena A. Vershinina, ${ }^{3}$ \\ Anna Maria Aloisi, ${ }^{4}$ and Vladimir A. Otellin ${ }^{1}$ \\ ${ }^{1}$ Laboratory of Ontogeny of the Nervous System, I. P. Pavlov Institute of Physiology, Russian Academy of Sciences, Nab. Makarova 6, \\ St. Petersburg 199034, Russia \\ ${ }^{2}$ Laboratory of Experimental Endocrinology, I. P. Pavlov Institute of Physiology, Russian Academy of Sciences, Nab. Makarova 6, \\ St. Petersburg 199034, Russia \\ ${ }^{3}$ Department of Applied Mathematics, I. P. Pavlov Institute of Physiology, Russian Academy of Sciences, Nab. Makarova 6, \\ St. Petersburg 199034, Russia \\ ${ }^{4}$ Department of Physiology, University of Siena, Neuroscience and Applied Physiology Section, Via Aldo Moro 2, 53100 Siena, Italy
}

Correspondence should be addressed to Irina P. Butkevich; but@kolt.infran.ru

Received 31 January 2013; Accepted 6 March 2013

Academic Editor: Metoda Lipnik-Stangelj

Copyright (C) 2013 Irina P. Butkevich et al. This is an open access article distributed under the Creative Commons Attribution License, which permits unrestricted use, distribution, and reproduction in any medium, provided the original work is properly cited.

\begin{abstract}
Our researches have shown that gestational stress causes exacerbation of inflammatory pain in the offspring; the maternal 5-HT1A agonist buspirone before the stress prevents the adverse effect. The serotonergic system and hypothalamo-pituitary-adrenal (HPA) axis are closely interrelated. However, interrelations between inflammatory pain and the HPA axis during the hyporeactive period of the latter have not been studied. The present research demonstrates that formalin-induced pain causes a gradual and prolonged increase in plasma corticosterone level in 7-day-old male rats; twenty-four hours after injection of formalin, the basal corticosterone level still exceeds the initial basal corticosterone value. Chronic treatments of rat dams with buspirone before restraint stress during gestation normalize in the offspring pain-like behavior and induce during the acute phase in the formalin test the stronger corticosterone increase as compared to the stress hormonal elevation in animals with other prenatal treatments. Negative correlation between plasma corticosterone level and the number of flexes+shakes is revealed in buspirone+stress rats. The new data enhance the idea about relativity of the HPA axis hyporeactive period and suggest that maternal buspirone prior to stress during gestation may enhance an adaptive mechanism of the inflammatory nociceptive system in the infant male offspring through activation of the HPA axis peripheral link.
\end{abstract}

\section{Introduction}

Interrelations between the serotonergic system and hypothalamo-pituitary-adrenal (HPA) axis determine the formation of mechanisms of stress adaptation [1-6]. Pain is a stress and therefore can activate the HPA axis [7-15]. In this case, inflammatory pain is still not clearly understood, and the data available are inconsistent $[9,14-17]$. In a widely used model of inflammatory pain, the formalin test, activation of the HPA axis with the nociceptive stimulus formalin has been shown on adult awake rodents and differences in the dynamics of release of ACTH and corticosterone in response to pain impact found [8, 9, 17-19]. The HPA axis during the postnatal development goes through the period of hyporesponsiveness, which extends from the second to fourteenth postnatal days and is characterized by a low level of the response of adrenals to many stress stimuli [20]. Investigations of formalin-induced pain effects on the HPA axis in infant rats could elucidate unexplored previously interrelations between the tonic nociceptive and stress systems during the period of hyporesponsiveness of the latter. We revealed for the first time that prenatal stress induces strengthening inflammatory pain-related response in the formalin test and decrease of adaptive capacities in 
infant rats; chronic injections of an agonist of serotonin (5-HT) receptors 1A (5-HT1A) buspirone to dams prior to stress during gestation cancel the adverse consequences of the stress in the offspring [21]. In prenatally stressed individuals, abnormalities in the HPA axis function [22] and neurotransmitter systems including the serotonergic one [23] were shown.

Serotonin acts as a growth factor in early cell division, migration, and differentiation in the brain specifically in development of the serotonergic system [24-27]. Many of regulator influences on developing neurons 5-HT mediates through presynaptic 5-HT1A autoreceptors in the raphe nuclei $[28,29]$. Later 5-HT and 5-HT1A receptors take part in many kinds of behavior. The serotonergic system plays an important role in pain transmission, its processing and regulation [30-33]. Buspirone, serotoninergic anxiolytic and antidepressant, mediates its effect through the serotonergic system and the HPA axis. There are synergistic interrelations between these systems impaired in prenatally stressed individuals [23, 34-36]. A peculiar mechanism of buspirone action has not been completely understood; it is also true for its analgesic effect. Studies of effects of buspirone, an agonist of presynaptic and a partial agonist of 5-HT1A receptors, on the nociceptive system are limited, and the results obtained do not coincide $[37,38]$. Prenatal effect of buspirone on the nociceptive system has not been studied until our researches. Activation of the antinociceptive descending serotonergic system and the decrease in hyperactivity of the HPA axis are considered as potential mechanisms of analgesic action of antidepressants. Activating effects of buspirone on the HPA system are found in adult persons [39]. It may be suggested that the period of hyporesponsiveness of the HPA, which is characterized by a low level of reaction of adrenals in response to many stress stimuli [20], will allow to prevent activating influences of buspirone on the HPA axis.

The aim of our work was to study effects of maternal buspirone prior to stress during gestation on the dynamics of the inflammatory pain-like behavior and stress response of corticosterone during the formalin test in the infant male rat offspring and also to evaluate correlation between pain-like and hormonal parameters.

\section{Materials and Methods}

2.1. Animals. All experimental procedures were approved by the Local Ethics Committee for Animal Experiments of the I. P. Pavlov Institute of Physiology and followed the guidelines published by the Committee for Research and Ethical Issues of the IASP on ethical standards for investigations of experimental pain in animals.

Adult female rats and male rats (Wistar) at the age of 90 days were obtained from the vivarium of the I. P. Pavlov Institute of Physiology RAN, St. Petersburg, Russia. Two days after adaptation, the rats were mated. The days of insemination and delivery were considered as gestational day (GD) 0 and postnatal day (PD) 0, respectively. All animals were maintained at constant temperature $\left(20-22^{\circ} \mathrm{C}\right)$ under the standard light-dark cycle (8.00 AM-8.00 PM) with unrestricted access to food and water. Seventeen rat dams (controls) were not exposed to any impacts during gestation. The equal number of remaining dams $(n=68)$ was randomly treated with the 5-HT1A agonist buspirone (buspirone hydrochloride, Sigma, $3 \mathrm{mg} / \mathrm{kg}, 1 \mathrm{~mL}$, i.p. at $9 \mathrm{AM}$ ) or with injection of saline (control animals from the same litters, in the same conditions of injections) from GD9 to GD21. A half of the treated rats from each group were randomly exposed to restraint stress for $60 \mathrm{~min}$ (in $5 \mathrm{~min}$ after buspirone injection) from GD15 to GD21. All influences on gestational females were identical to those used in our previous study [21]. The dose of buspirone was sufficient for inducing an anxiolytic effect in adult rats [40] and did not exceed the dose used for pregnant rat dams to protect the fetal serotonergic system against damaging effects of in utero ethanol exposure [41]. It should be noted that such dose of buspirone was not able to implicate dopamine and norepinephrine in the mediation of buspirone effects $[42,43]$. Litters were called to 8 pups ( 4 females and 4 males, as far as possible) in 48 hours after birth. In the study, 7-day-old males born to the dams with the above-mentioned treatments during gestation and to control dams were used; females and remaining males were used in other researches. There were 245 males offspring of control, saline, saline + stress, buspirone, and buspirone + stress dams in the study with formalin injection (about 6-8 males per a group, no more than 3 animals from one dam); in addition, 80 male rats from the same litters were used as control for the formalin, with saline injection into the hind limb.

\subsection{Experimental Formalin-Induced Inflammatory Pain in} Infant Male Rats. Formalin test is widely used for evaluation of tonic inflammatory pain and analgesic effects of various pharmacological drugs [9, 44-47]. Flexing and shaking behaviors are the specific expression of inflammatory painrelated behavior in the formalin test in both infant and adult rats $[44,45,48,49]$; we used the formalin test as previously described [21]. The formalin test allows evaluating acute nociception (the first phase, 5-10 min after formalin injection), tonic persistent nociception (the second phase about 30-40 $\mathrm{min}$ ), and functional activity of the descending serotonergic inhibitory system (the interphase about 3$10 \mathrm{~min})$. The second phase appears during postnatal development when the descending serotonergic inhibitory system matures $[45,46]$. Characteristics of the phases depend on many factors including age and sex [50].

Each male rat was taken from the nest, injected intraplantarly to the left hindpaw with formalin solution $(2.5 \%, 10 \mu \mathrm{L})$, and placed singly in a warm $\left(25^{\circ} \mathrm{C}\right)$ chamber $(25 \times 20 \times 10 \mathrm{~cm})$ with transparent glass walls encircled by mirrors to improve the observation of the animal's behavior $[21,51]$. The number of flexes + shakes was recorded using a computer program that allows recording, quantifying, and analyzing the painrelated behavior. In each group of the males, the number of flexes + shakes was averaged for 3, 9, 21, 30, and 60 min after formalin injection. Each animal was used only once.

2.3. Corticosterone Determination in Infant Male Rats. Blood samples were collected by decapitation in the rats with different prenatal treatments and in controls at 09:00-10:00 before 
and 24 hours after the formalin test for determination of basal plasma corticosterone levels. During the formalin-induced pain, blood sampling by decapitation occurred at 3, 9, 21, 30, and $60 \mathrm{~min}$ after formalin injection. The blood samples were centrifuged and the plasma was kept at $-20^{\circ} \mathrm{C}$ no more than a week. The plasma corticosterone (SIGMA-ALDRICH, USA) levels $(\mu \mathrm{g} / \mathrm{dL})$ were measured by microfluorometry [52].

2.4. Statistical Analysis. Data are presented as mean \pm S.D. Formalin-evoked flexing + shaking, and corticosterone responses were analyzed by two-way ANOVA, with treatment (control, saline, saline + stress, buspirone, and buspirone + stress) and time as factors. Behavioral and corticosterone responses during $3,9,21,30$, and 60 minutes were separately evaluated. Comparisons between the basal levels and the data over time as well as comparisons between groups with different types of treatment were conducted using tests of simple effects. Besides pairwise comparisons, $t$-test and Mann-Whitney test were performed. Pearson and Spearman Correlations were calculated to estimate relationships between behavioral and hormonal variables. For all tests, $P<$ 0.05 was considered to be statistically significant.

\section{Results}

Two-way ANOVA applied to pain-like responses (Figure 1) resulted in a significant effect of the factor prenatal treatments $(\mathrm{F}(4,114)=5.094, P=0.001) ;(\mathrm{F}(3,114)=56.545, P<0.001)$. Tests of simple effects showed a significant increase in the number of flexes + shakes at 9,30 , and 60 min after formalin injection in saline + stress as compared to saline $(P<0.05$, $P<0.05$, and $P=0.014$, resp.) and in saline + stress as compared to the control $(P=0.002, P=0.03$, resp. $)$ (Figure 1). Tests of simple effects showed a decrease in the number of flexes + shakes at 9,21,30, and $60 \mathrm{~min}$ after formalin injection in buspirone + stress as compared to saline + stress $(P=0.002, P<0.05, P<0.05$, and $P=0.002$, resp. $)$ (Figure 1).

Two-way ANOVA applied to the level of plasma corticosterone (Figure 2 ) resulted in a significant effect of the factor prenatal treatments $(\mathrm{F}(4,170)=2.706, P=0.002)$ and time $(\mathrm{F}(5,170)=22.574, P<0.001)$. The significant effects of factor prenatal treatment on dependent variable corticosterone were revealed at 3 and $9 \min (\mathrm{F}(4,170)=2.322$, $P<0.05 ; \mathrm{F}(4,170)=3.634, P<0.007$, resp. $)$. Tests of simple effects showed the corticosterone level at $3 \mathrm{~min}$ after formalin injection was higher than basal level $(P=0.037)$ in buspirone + stress males; during the following time periods $(9,21,30$, and $60 \mathrm{~min}$ ), corticosterone was higher than basal level in animals with all prenatal treatments $(P<0.05)$ (Figure 2$)$. Tests of simple effects (pairwise comparisons) or/and MannWhitney test showed that only in buspirone + stress males at 3 and $9 \mathrm{~min}$ after formalin injection, the corticosterone level was higher than similar hormonal level in animals with all different prenatal treatments $(P<0.05)$. During the following time course of formalin-induced pain, there were no differences in the stress level of hormone between animals with different prenatal treatments. Tests of simple effects (pairwise comparisons) or/and Mann-Whitney test showed that in the course of inflammatory pain, the level of plasma corticosterone gradually increased $(\mathrm{F} 5,170)=22.574$, $P<0.001$ ) and to the end of the formalin test (at $60 \mathrm{~min}$ ) was significantly higher than basal level $(P=0.001)$. Pairwise comparisons showed that basal level $24 \mathrm{~h}$ after the formalin test was greater than that prior to the formalin test $(P=0.001)$ in animals with all prenatal treatments $(P<0.05)$ (Figure 2$)$.

There were no significant differences in indices under study in buspirone, saline, and control animals.

Correlation between plasma corticosterone level and the number of flexes + shakes was revealed in buspirone + stress male rats at $3(-r=0.925, P=0.008), 9 \min (-r=0.937, P=$ $0.002)$, and $60 \min (-r=0.690, P=0.05)$ and in control rats at $3 \mathrm{~min}(-r=0.90, P=0.037)$ after injection of formalin.

Injection of saline to the left hindpaw (controls for formalin injection) resulted in a few weak flexes + shakes during some first minutes after injection only in prenatally stressed males. Corticosterone response to pain was a specific reaction; in control animals, an increase in the plasma corticosterone in response to the procedure of saline injection into the paw was less prolonged (no more than $30 \mathrm{~min}$ ) and did not exceed the value of corticosterone response to formalin-induced pain (the data are not shown in the table).

\section{Discussion}

The dynamics of corticosterone stress response to inflammatory pain and participation of 5-HT1A receptors in it were investigated in the present study in 7-day-old male rats with various prenatal treatments. Evidence of increased formalin-induced pain in prenatally stressed animals is in agreement with the data that we obtained earlier [21]. Chronic treatments of rat dams with the 5-HT1A agonist buspirone prior to stress during gestational period increased resistance of the tonic nociceptive system normalizing behavior in the inflammatory pain model and changed the time course of stress corticosterone response to formalin-induced pain in the offspring.

Before our studies, in a widely accepted model of inflammatory pain, the formalin test, it was demonstrated in adult awake rats that the nociceptive stimulus formalin induced activation of the HPA axis and increased concentration of ACTH and corticosterone $[9,13,19]$. Interestingly, the authors that found the peak of the corticosterone release at $30 \mathrm{~min}$ and its restored level at $80 \mathrm{~min}$ after formalin injection concluded that the resulting release of corticosterone is not antinociceptive as neither adrenalectomy nor high-dose dexamethasone changed behavioral nociceptive responses [9]. It is worthy to note that peaked time in release of corticosterone in response to the formalin test as well as the time of the hormonal restoration level after formalin injection vary according to the authors from the 15-60 min to $60-120 \mathrm{~min}$, respectively $[9,13,19]$. These differences may be attributed to peculiarities of the formalin test. The behavioral response in the formalin test, represented by acute and tonic phases of different chemical nature, depends on concentrations and volumes of formalin solution, a place 

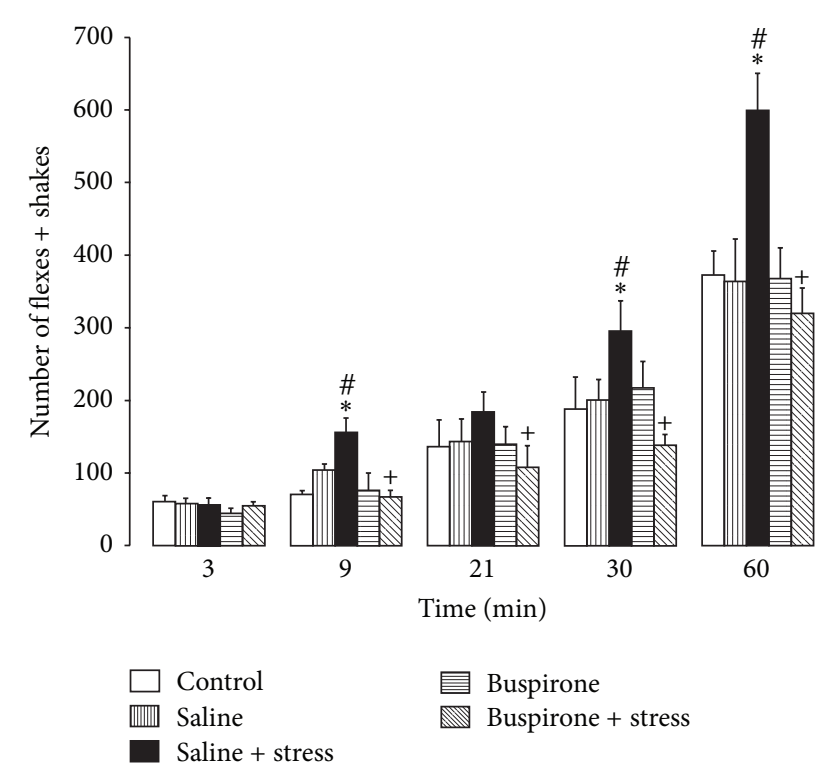

FIGURE 1: Pain-like responses recorded over different periods of time $(3,9,21,30$, and $60 \mathrm{~min}$ ) after injection of formalin (mean \pm SEM) in 7-day-old male rats with different prenatal treatments. ${ }^{*} P<0.05$ different from saline; ${ }^{+} P<0.05$ different from saline + stress; ${ }^{\#} P<$ 0.05 different from controls.

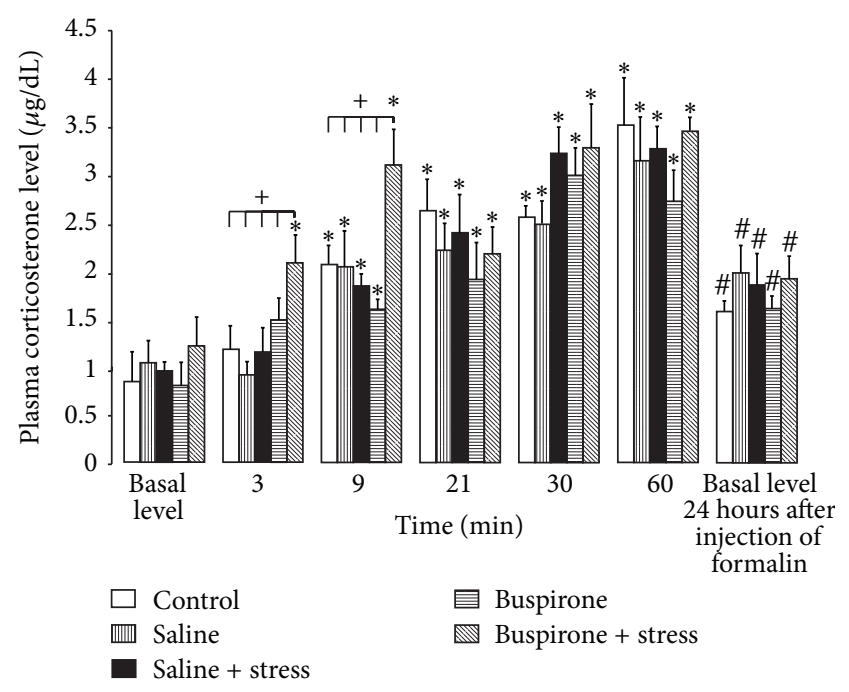

Figure 2: Basal levels of corticosterone and plasma corticosterone levels $(\mu \mathrm{g} / \mathrm{dl})$ determined 3, 9, 21, 30, and 60 min after injection of formalin (mean \pm SEM) in 7-day-old male rats with different prenatal treatments. ${ }^{*} \mathrm{P}<0.05$ different from the basal level; ${ }^{+} \mathrm{P}<$ 0.05 different from the control, saline, saline + stress, and buspirone; ${ }^{\#} P<0.05$ different from the basal level before injection of formalin.

of its injection, temperature in the room, a strain of rats, and conditions of experimental performances $[9,50,53$, 54]. These factors determine involvement in the response of various mediators influencing the intensity and dynamics of release of corticosterone.

Our study is the first to evaluate the dynamics of corticosterone release in conditions of inflammatory pain in infant rats during the hyporesponsive period of the HPA axis [20]. The new data obtained testify that inflammatory formalininduced pain evokes the stress response of corticosterone in male rats during the hyporesponsive period of the HPA axis. This reaction is a specific reaction to pain; in control animals, an increase in the plasma corticosterone in response to the procedure of saline injection into the paw was less prolonged and weaker than the hormonal response to formalin-induced pain. We have revealed that the characteristic feature of the dynamics of corticosterone response to inflammatory pain in infant rats is a gradual increase of hormonal release in the formalin test, so to the end of the response the level of corticosterone considerably exceeded its initial level. Most importantly, the results indicate that 24 hours after the formalin test, the corticosterone level still exceeds the basal corticosterone value before the formalin test in males of all the groups under study. This fact cannot be associated with an increase in corticosterone basal level in intact 8-day-old male rats as compared to that in 7-day-olds, as available data and our own results indicate equal value in the basal level of plasma corticosterone in 5-8-day-old male rats that were not exposed to any prenatal impacts [55]. Based on these results, we conclude that the peripheral link of the HPA axis responds to inflammatory pain in the formalin test in infant rats with a prolonged reaction. Experimental data reported here enhance the idea of relativity of hyporesponsive period of the HPA axis [20]. Up to now, there has not been any detailed work done to find a clear explanation for this period in the development of the HPA axis.

The results obtained provide new important information that maternal 5-HT1A agonist buspirone prior to stress during gestation induces in the offspring during the acute phase in the formalin test the stronger corticosterone increase as compared to the stress hormonal elevation in animals with other prenatal treatments. In the following time periods of formalin-induced pain, the animals with different prenatal treatments do not show significant differences in stress corticosterone level. Negative correlation revealed between the corticosterone concentration and the number of flexes + shakes during the first nine minutes after injection of formalin in buspirone + stress male rats is noteworthy. These results suggest that activation of the corticosterone release via 5-HT1A receptors may facilitate some adaptive mechanisms associated with a decrease of inflammatory pain in buspirone + stress rats.

There are multiple pathways through which 5-HT and its agonists may stimulate the HPA axis [56]. It is shown that formalin activates ascending ways to the HPA [57]. The chemical stimulus formalin induces appearance of "inflammatory soup" from various chemical substances including 5HT released from platelets and also activation of neutrophils and leucocytes that produce proinflammatory cytokines IL6 [17]. Cytokines contribute to the increase in ACTH and corticosterone [17] and to the exacerbation of nociceptive processing [58]. Interaction between the HPA axis and 5HT system would be dependent on concentration of 5-HT released from platelets during inflammation which reaches the central nervous sites, but this question is poorly known. Both systems are highly plastic during maturation [6], and 
prenatal stress impairs interaction between the HPA axis and 5 -HT system and alters their functional activity in adults $[2,35]$. The expression of $5-\mathrm{HT} 1 \mathrm{~A}$ receptors is found during the initial stages of prenatal development of the hippocampus [59] and prenatal stress impairs their development [60]. There is evidence that buspirone penetrates through the placental and blood brain barriers [61] and is able to exert the protective effects presumably through its ability to overcome the deficit of fetal serotonin and to stimulate fetal 5-HT1A receptors [62]. Further studies are needed to evaluate influences of maternal buspirone prior to stress during gestation to the HPA axis response during the inflammatory pain immediately after finishing the period of responsiveness in the HPA axis development. Thus, new data indicate an important role of 5-HT1A receptors in the development of close relationships between the HPA axis and tonic nociceptive system that mediate adaptation of organism to extreme conditions.

\section{Summary}

The formalin-induced pain causes a gradual and prolonged increase in plasma corticosterone level during the persistent pain-like behavior in 7-day-old male rats. Chronic treatments of rat dams with buspirone before restraint stress during gestation normalize in the offspring inflammatory pain behavior and induce during the acute phase in the formalin test the stronger corticosterone increase as compared to the stress hormonal elevation in animals with other prenatal treatments. Buspirone + stress rats display the negative correlation between plasma corticosterone level and the number of flexes + shakes. Thus, the new data enhance the idea about relativity of the HPA axis hyporeactive period and suggest that maternal buspirone prior to stress during gestation may enhance an adaptive mechanism of the inflammatory nociceptive system in the infant male offspring through activation of the HPA axis peripheral link.

\section{Conflict of Interest}

The authors declare that they have no conflict of interest.

\section{Acknowledgment}

The reported study was supported by RFBR, Research Project no. 11-04-01381.

\section{References}

[1] F. Chaouloff, "Serotonin, stress and corticoids," Journal of Psychopharmacology, vol. 14, no. 2, pp. 139-151, 2000.

[2] H. Takeda, M. Tsuji, and T. Matsumiya, "Formation mechanisms of stress adaption: role of functional coupling of glucocorticoids and brain serotonergic nervous system," Japanese Journal of Psychopharmacology, vol. 20, no. 3, pp. 83-91, 2000.

[3] A. H. Veenema, J. M. Koolhaas, and E. R. de Kloet, "Basal and stress-induced differences in HPA axis, 5-HT responsiveness, and hippocampal cell proliferation in two mouse lines," Annals of the New York Academy of Sciences, vol. 1018, pp. 255-265, 2004.
[4] L. Lanfumey, C. Mannoury La Cour, N. Froger, and M. Hamon, "5-HT-HPA Interactions in Two Models of Transgenic Mice Relevant to Major Depression," Neurochemical Research, vol. 25, no. 9-10, pp. 1199-1206, 2000.

[5] M. Pompili, G. Serafini, M. Innamorati et al., "The hypothalamic-pituitary-adrenal axis and serotonin abnormalities: a selective overview for the implications of suicide prevention," European Archives of Psychiatry and Clinical Neuroscience, vol. 260, no. 8, pp. 583-600, 2010.

[6] D. M. Vázquez, C. R. Neal Jr., P. D. Patel et al., "Regulation of corticoid and serotonin receptor brain system following early life exposure of glucocorticoids: long term implications for the neurobiology of mood," Psychoneuroendocrinology, vol. 37, no. 3, pp. 421-437, 2012.

[7] M. Strittmatter, M. T. Grauer, M. C. Fischer et al., "Autonomic nervous system and neuroendocrine changes in patients with idiopathic trigeminal neuralgia," Cephalalgia, vol. 16, no. 7, pp. 476-480, 1996.

[8] K. Pacak, M. Palkovits, G. Yadid et al., "Heterogeneous neurochemical responses to different stressors: a test of Selye's doctrine of nonspecificity, American Journal of Physiology, vol. 275, no. 4, part 2, pp. 1247-1255, 1998.

[9] B. K. Taylor, S. F. Akana, M. A. Peterson, M. F. Dallman, and A. I. Basbaum, "Pituitary-adrenocortical responses to persistent noxious stimuli in the awake rat: endogenous corticosterone does not reduce nociception in the formalin test," Endocrinology, vol. 139, no. 5, pp. 2407-2413, 1998.

[10] Y. Shavit, J. Weidenfeld, F. G. Dekeyser et al., "Effects of surgical stress on brain prostaglandin $\mathrm{E} 2$ production and on the pituitary-adrenal axis: attenuation by preemptive analgesia and by central amygdala lesion," Brain Research, vol. 1047, no. 1, pp. 10-17, 2005.

[11] F. Anton, "Chronic stress and pain-a plea for a concerted research program," Pain, vol. 143, no. 3, pp. 163-164, 2009.

[12] R. Goldkuhl, A. Klockars, H. E. Carlsson, J. Hau, and K. S. P. Abelson, "Impact of surgical severity and analgesic treatment on plasma corticosterone in rats during surgery," European Surgical Research, vol. 44, no. 2, pp. 117-123, 2010.

[13] T. Rouwette, K. Klemann, B. Gaszner et al., "Differential responses of corticotropin-releasing factor and urocortin 1 to acute pain stress in the rat brain," Neuroscience, vol. 183, pp. 1524, 2011.

[14] M. Benedetti, R. Merino, R. Kusuda et al., "Plasma corticosterone levels in mouse models of pain," European Journal of Pain, vol. 16, no. 6, pp. 803-815, 2012.

[15] P.-E. Juif, F. Anton, and U. Hanesch, "Pain behavior and spinal cell activation due to carrageenan-induced inflammation in two inbred rat strains with differential hypothalamic-pituitaryadrenal axis reactivity," Physiology and Behavior, vol. 105, no. 4, pp. 901-908, 2012.

[16] E. M. Sternberg, J. M. Hill, G. P. Chrousos et al., "Inflammatory mediator-induced hypothalamic-pituitary-adrenal axis activation is defective in streptococcal cell wall arthritis-susceptible Lewis rats," Proceedings of the National Academy of Sciences of the United States of America, vol. 86, no. 7, pp. 2374-2378, 1989.

[17] A. M. Aloisi, M. E. Albonetti, M. Muscettola, F. Facchinetti, C. Tanganelli, and G. Carli, "Effects of formalin-induced pain on ACTH, beta-endorphin, corticosterone and interleukin-6 plasma levels in rats," Neuroendocrinology, vol. 62, no. 1, pp. 1318, 1995. 
[18] K. C. Vissers, R. F. de Jongh, B. J. Crul et al., "Adrenalectomy affects pain behavior of rats after formalin injection," Life Sciences, vol. 74, no. 10, pp. 1243-1251, 2004.

[19] B. Mravec, I. Bodnár, A. Tillinger et al., "Prolactin response to formalin is related to the acute nociceptive response and it is attenuated by combined application of different stressors," Neuroendocrinology, vol. 86, no. 2, pp. 69-76, 2007.

[20] M. F. Dallman, "Editorial: moments in time-the neonatal rat hypothalamo-pituitary-adrenal axis," Endocrinology, vol. 141, no. 5, pp. 1590-1592, 2000.

[21] I. P. Butkevich, V. A. Mikhailenko, E. A. Vershinina et al., "Buspirone before prenatal stress protects against adverse effects of stress on emotional and inflammatory pain behaviors in infant rats: age and sex differences," Brain Research, vol. 1419, no. 1, pp. 76-84, 2011.

[22] M. Weinstock, "The long-term behavioral consequences of prenatal stress," Neuroscience \& Biobehavioral Reviews, vol. 32, no. 6, pp. 1073-1083, 2008.

[23] A. Hayashi, M. Nagaoka, K. Yamada, Y. Ichitani, Y. Miake, and N. Okado, "Maternal stress induces synaptic loss and developmental disabilities of offspring," International Journal of Developmental Neuroscience, vol. 16, no. 3-4, pp. 209-216, 1998.

[24] J. M. Lauder, "Ontogeny of the serotonergic system in the rat: serotonin as a developmental signal," Annals of the New York Academy of Sciences, vol. 600, pp. 297-313, 1990.

[25] E. C. Azmitia, "Modern views on an ancient chemical: serotonin effects on cell proliferation, maturation, and apoptosis," Brain Research Bulletin, vol. 56, no. 5, pp. 413-424, 2001.

[26] P. Gaspar and C. Lillesaar, "Probing the diversity of serotonin neurons," Philosophical Transactions of the Royal Society, vol. 367, no. 1601, pp. 2382-2394, 2012.

[27] T. F. Oberlander, "Fetal serotonin signaling: setting pathways for early childhood development and behavior," Journal of Adolescent Health, vol. 51, no. 2, pp. 9-16, 2012.

[28] A. Bonnin, N. Goeden, K. Chen et al., "A transient placental source of serotonin for the fetal forebrain," Nature, vol. 472, no. 7343, pp. 347-350, 2011.

[29] P. M. Whitaker-Azmitia, M. Druse, P. Walker, and J. M. Lauder, "Serotonin as a developmental signal," Behavioural Brain Research, vol. 73, no. 1-2, pp. 19-29, 1995.

[30] P. K. Eide and K. Hole, "The role of 5-hydroxytryptamine (5HT) receptor subtypes and plasticity in the 5-HT systems in the regulation of nociceptive sensitivity," Cephalalgia, vol. 13, no. 2 , pp. 75-85, 1993.

[31] M. Hamon and S. Bourgoin, "Serotonin and its receptors in pain control," in Novel Aspects of Pain Management, J. Sawynok and A. Cowan, Eds., pp. 203-228, John Wiley \& Sons, New York, NY, USA, 1999.

[32] F. C. Colpaert, M. Hamon, and Z. Wiesenfeld-Hallin, “5-HT1A receptors in chronic pain processing and control," in Proceedings of the 11th World Congress on Pain, H. Flor, E. Kalso, and J. O. Dostrovsky, Eds., IASP Press, Seattle, Wash, USA, 2006.

[33] J. M. Braz and A. I. Basbaum, "Genetically expressed transneuronal tracer reveals direct and indirect serotonergic descending control circuits," Journal of Comparative Neurology, vol. 507, no. 6, pp. 1990-2003, 2008.

[34] M. Weinstock, "Intrauterine factors as determinants of depressive disorder," Israel Journal of Psychiatry \& Related Sciences, vol. 47, no. 1, pp. 36-45, 2010.

[35] H. Belay, C. L. Burton, V. Lovic, M. J. Meaney, M. Sokolowski, and A. S. Fleming, "Early Adversity and Serotonin Transporter
Genotype Interact With Hippocampal Glucocorticoid Receptor mRNA Expression, Corticosterone, and Behavior in Adult Male Rats," Behavioral Neuroscience, vol. 125, no. 2, pp. 150-160, 2011.

[36] K. Miyagawa, M. Tsuji, K. Fujimori, Y. Saito, and H. Takeda, "Prenatal stress induces anxiety-like behavior together with the disruption of central serotonin neurons in mice," Neuroscience Research, vol. 70, no. 1, pp. 111-117, 2011.

[37] D. V. Sivarao, K. Newberry, and N. J. Lodge, "Effect of the 5HT1A receptor partial agonist buspirone on colorectal distension-induced pseudoaffective and behavioral responses in the female Wistar rat," European Journal of Pharmacology, vol. 494, no. 1, pp. 23-29, 2004.

[38] G. Pavlaković, J. Tigges, and T. A. Crozier, "Effect of buspirone on thermal sensory and pain thresholds in human volunteers," BMC Clinical Pharmacology, vol. 9, article 12, 2009.

[39] H. M. van Praag, "Can stress cause depression?" World Journal of Biological Psychiatry, vol. 6, no. s2, pp. 5-22, 2005.

[40] L. W. Lim, Y. Temel, V. Visser-Vandewalle et al., "Effect of buspirone on the behavioral regulation of rats in low versus high anxiety conditions," Arzneimittelforschung, vol. 58, no. 6, pp. 269-276, 2008.

[41] J. A. Kim and M. J. Druse, "Protective effects of maternal buspirone treatment on serotonin reuptake sites in ethanolexposed offspring," Developmental Brain Research, vol. 92, no. 2, pp. 190-198, 1996.

[42] M. Cimino, F. Ponzio, and G. Achilli, "Dopaminergic effects of buspirone, a novel anxiolytic agent," Biochemical Pharmacology, vol. 32, no. 6, pp. 1069-1074, 1983.

[43] T. J. Rimeli, D. E. Henry, D. K. H. Lee et al., "Tissuedependent alpha adrenoceptor activity of buspirone and related compounds," Journal of Pharmacology and Experimental Therapeutics, vol. 241, no. 3, pp. 771-778, 1987.

[44] H. Wheeler-Aceto and A. Cowan, "Standardization of the rat paw formalin test for the evaluation of analgesics," Psychopharmacology, vol. 104, no. 1, pp. 35-44, 1991.

[45] E. R. Guy and F. V. Abbott, "The behavioral response to formalin in preweanling rats," Pain, vol. 51, no. 1, pp. 81-90, 1992.

[46] G. A. Barr, "Maturation of the biphasic behavioral and heart rate response in the formalin test," Pharmacology Biochemistry and Behavior, vol. 60, no. 2, pp. 329-335, 1998.

[47] T. Yamada, D. Zuo, T. Yamamoto et al., "NAAG peptidase inhibition in the periaqueductal gray and rostral ventromedial medulla reduces flinching in the formalin model of inflammation," Molecular Pain, vol. 8, article 67, 2012.

[48] G. A. Barr, "Formalin-induced c-fos expression in the brain of infant rats," Journal of Pain, vol. 12, no. 2, pp. 263-271, 2011.

[49] I. Zouikr, M. A. Tadros, V. L. Clifton et al., "Low formalin concentrations induce fine-tuned responses that are sex and agedependent: a developmental study," PLoS One, vol. 8, no. 1, article e53384, 2013.

[50] A. Tjolsen, O. G. Berge, S. Hunskaar, J. H. Rosland, and K. Hole, "The formalin test: an evaluation of the method," Pain, vol. 51, no. 1, pp. 5-17, 1992.

[51] I. P. Butkevich, V. A. Mikhailenko, E. A. Vershinina, P. O. Semionov, V. A. Otellin, and A. M. Aloisi, "Heterogeneity of the infant stage of rat development: inflammatory pain response, depression-related behavior, and effects of prenatal stress," Brain Research, vol. 1286, pp. 53-59, 2009.

[52] L. P. Filaretova, A. A. Filaretov, and G. B. Makara, "Corticosterone increase inhibits stress-induced gastric erosions in rats," American Journal of Physiology, vol. 274, no. 6, pp. G1024G1030, 1998. 
[53] F. V. Abbott, K. B. J. Franklin, and R. F. Westbrook, "The formalin test: scoring properties of the first and second phases of the pain response in rats," Pain, vol. 60, no. 1, pp. 91-102, 1995.

[54] F. Capone and A. M. Aloisi, "Refinement of pain evaluation techniques. The formalin test," Annali dell'Istituto Superiore di Sanita, vol. 40, no. 2, pp. 223-229, 2004.

[55] D. L. A. van den Hove, H. W. M. Steinbusch, A. Scheepens et al., "Prenatal stress and neonatal rat brain development," Neuroscience, vol. 137, no. 1, pp. 145-155, 2006.

[56] B. L. Jacobs and E. C. Azmitia, "Structure and function of the brain serotonin system," Physiological Reviews, vol. 72, no. 1, pp. 165-229, 1992.

[57] M. Palkovits, J. S. Baffi, and K. Pacak, "The role of ascending neuronal pathways in stress-induced release of noradrenaline in the hypothalamic paraventricular nucleus of rats," Journal of Neuroendocrinology, vol. 11, no. 7, pp. 529-539, 1999.

[58] Y. Lu, L. Zhu, and Y. J. Gao, "Pain-related aversion induces astrocytic reaction and proinflammatory cytokine expression in the anterior cingulate cortex in rats," Brain Research Bulletin, vol. 84, no. 2, pp. 178-182, 2011.

[59] T. D. Patel and F. C. Zhou, "Ontogeny of 5-HT1A receptor expression in the developing hippocampus," Developmental Brain Research, vol. 157, no. 1, pp. 42-57, 2005.

[60] D. L. A. van den Hove, J. M. Lauder, A. Scheepens, J. Prickaerts, C. E. Blanco, and H. W. M. Steinbusch, "Prenatal stress in the rat alters 5-HT1A receptor binding in the ventral hippocampus," Brain Research, vol. 1090, no. 1, pp. 29-34, 2006.

[61] A. Boyd, Psychiatric Nursing, Lippincott Williams \& Wilkins, Philadelphia, Pa, USA, 2008.

[62] J. A. Kim, R. A. Gillespie, and M. J. Druse, "Effects of maternal ethanol consumption and buspirone treatment on 5- HT1A and 5-HT2A receptors in offspring," Alcoholism, vol. 21, no. 7, pp. 1169-1178, 1997. 


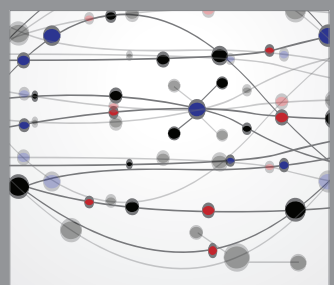

The Scientific World Journal
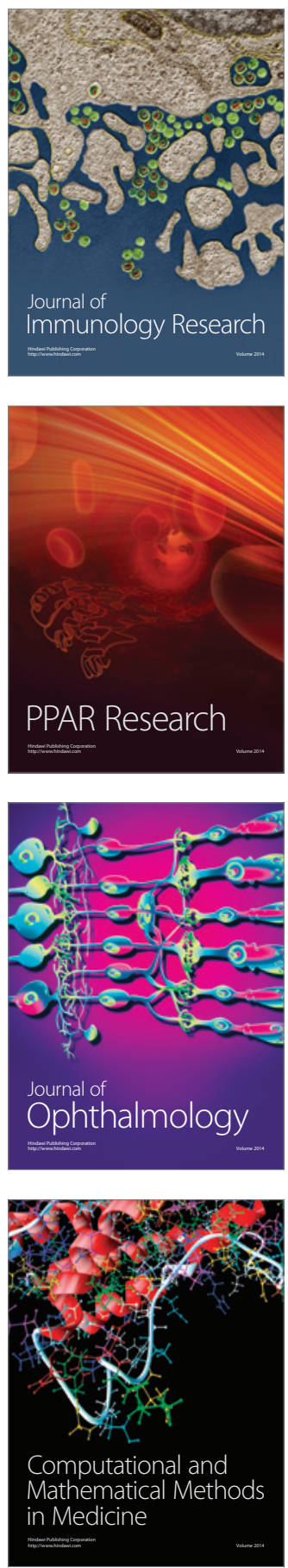

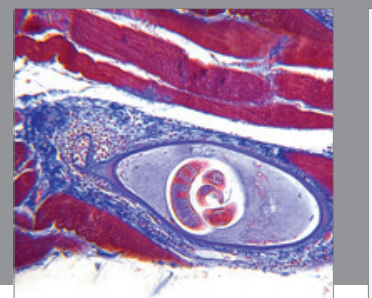

Gastroenterology

Research and Practice
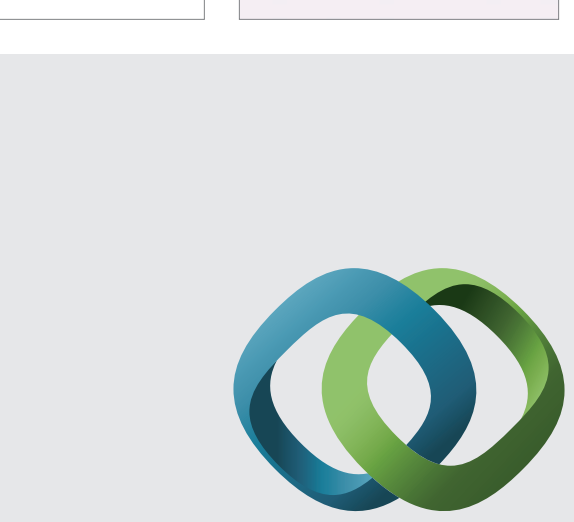

\section{Hindawi}

Submit your manuscripts at

http://www.hindawi.com
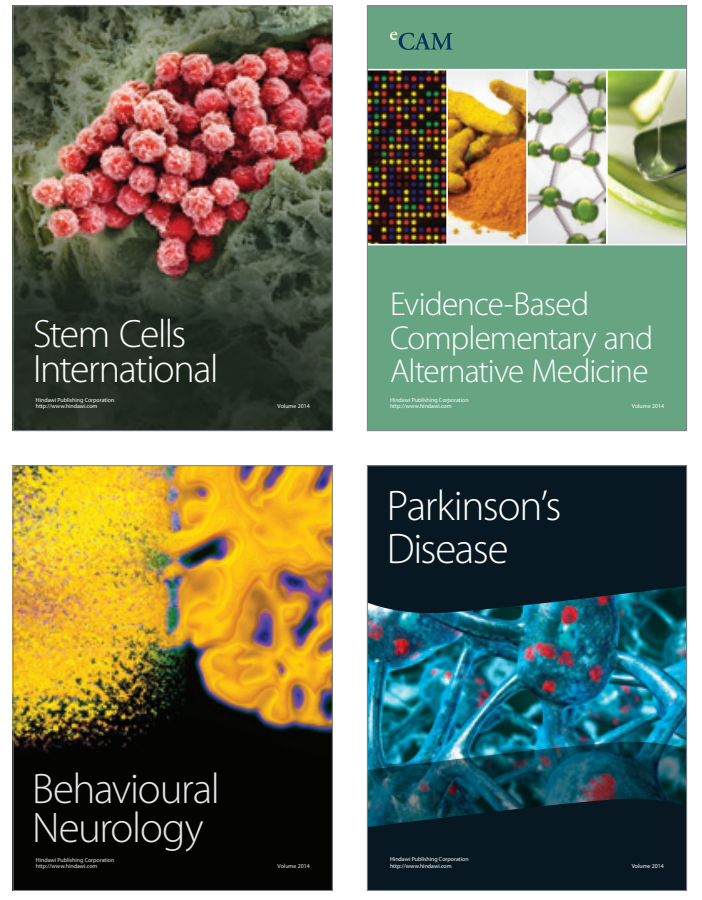
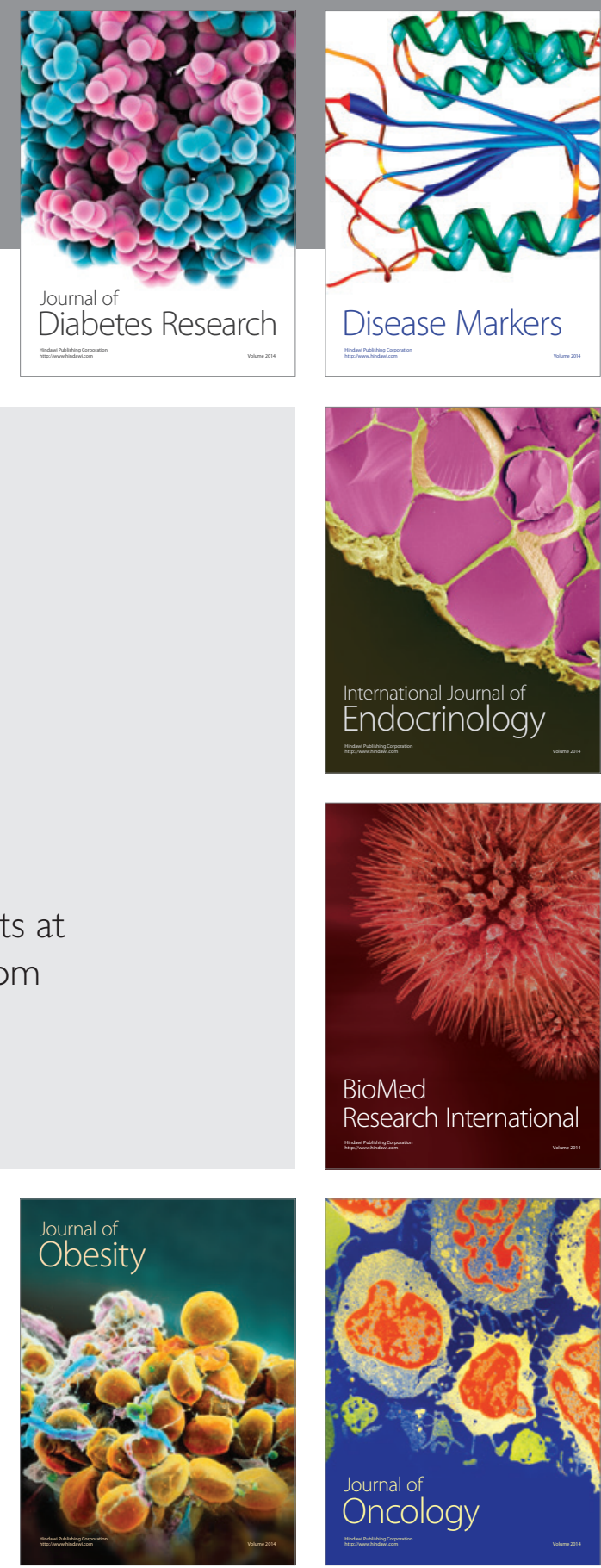

Disease Markers
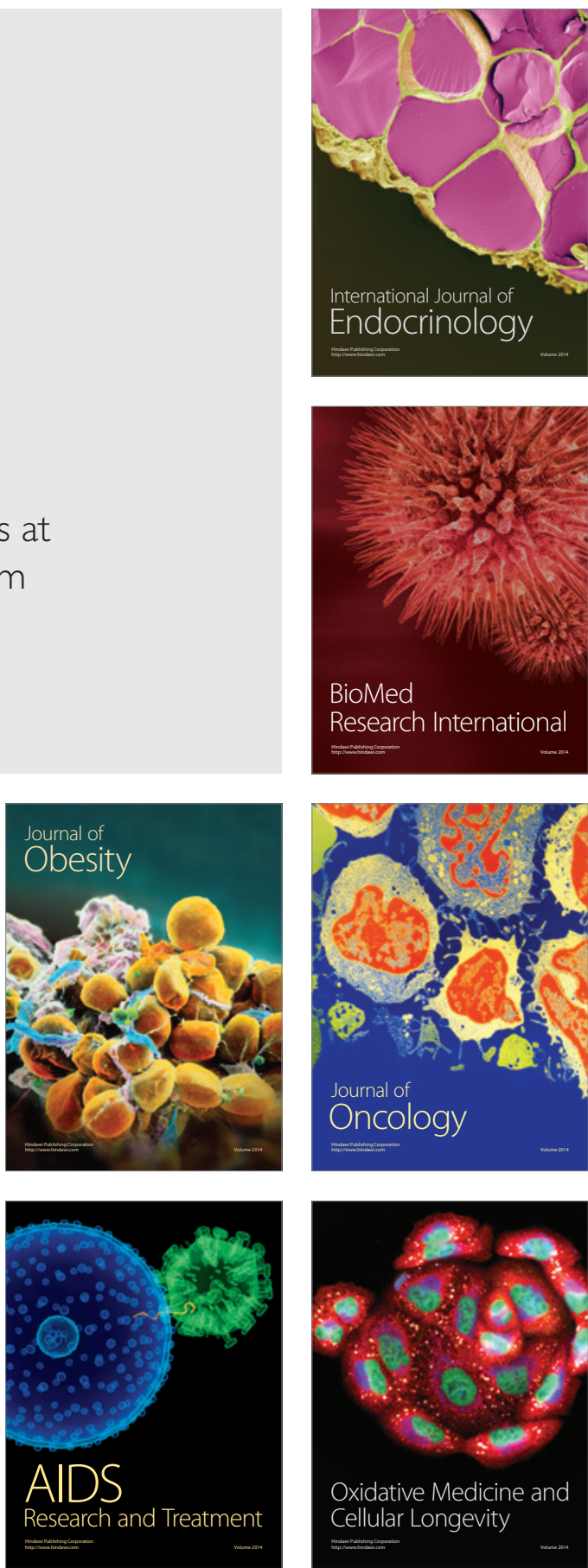